\title{
The cholesterol-raising effect of coffee in the Syrian hamster
}

\author{
BY T. A. B. SANDERS AND SANOJA SANDARADURA \\ Department of Nutrition and Dietetics, King's College, University of London, Campden Hill Road, \\ London W8 7 AH
}

(Received 24 June 1991-Accepted I August 199I)

\begin{abstract}
Adult male Syrian hamsters were fed on a high-fat diet with or without access to boiled coffee. Plasma total, low-density-lipoprotein- and high-density-lipoprotein-cholesterol and triacylglycerol concentrations were increased by the coffee and very-low-density-lipoprotein-cholesterol concentrations were lowered. It is concluded that the Syrian hamster is a suitable animal model in which to study the hypercholesterolaemic effect of coffee.
\end{abstract}

Cholesterol: Lipoproteins: Coffee: Syrian hamster

Cross-sectional studies within populations have identified coffee consumption as a powerful predictor of low-density-lipoprotein (LDL)-cholesterol concentration (Williams et al. 1985). Thelle et al. (1987), in their review, conclude that there is a direct relationship between coffee consumption and total cholesterol concentration. The strongest associations of coffee and cholesterol have been found in Scandinavia. A study from Tromsø reported a $10 \%$ increase in serum cholesterol in men and an $8 \%$ increase in women when people not drinking coffee were compared with those drinking nine cups or more per $\mathrm{d}$; for boiled coffee the association was even stronger (12\% in men and $10 \%$ in women). Another prospective Norwegian study found that plasma cholesterol concentrations in men and women increased from lowest to highest coffee consumption (13.1 and $10.9 \%$ respectively; Tverdal et al. 1990). Bak \& Grobbee (1989) demonstrated that the method of preparation of coffee is critical: boiled but not filtered coffee increased plasma total and LDLcholesterol concentrations in man. Zock et al. (1990) reported that a lipid-rich fraction from boiled coffee possessed this plasma cholesterol-raising effect.

The identification of the material causing the elevation of plasma cholesterol concentration, using human volunteers, poses a number of problems both in terms of time and cost. Animal models have been used with success to study dietary effects and have led to the identification of vitamin $\mathrm{C}$ and thiamin (Widdowson, 1986). Rats and rabbits are unsuitable models for studying lipoprotein metabolism; however, the Syrian hamster responds to variations in fat intake in an essentially identical manner to that seen in man (Spady \& Dietschy, 1988, 1989). The study reported here demonstrates that this animal model is suitable for studying the hypercholesterolaemic effects of boiled coffee.

\section{MATERIALS AND METHODS}

Adult male Syrian hamsters were obtained from Wrights of Essex, Chelmsford. The animals were individually housed and fed on a semi-synthetic diet set in gelatine. Powdered diet consisting of $(\mathrm{g} / \mathrm{kg})$ : casein 200 , lard 200 , starch 439 , sucrose 100 , mineral mix 40 , vitamin mix 20 , DL-methionine 1 , cholesterol 1 , was set in gelatine by mixing it $(1: 1, \mathrm{v} / \mathrm{v})$ with a 60 g gelatine/ 1 solution. Once the gelatine had set the diet was cut into approximately 
Table 1. Body-weight, liver weight, food and fuid intakes in Syrian hamsters fed on boiled coffee or control solutiont

(Mean values with their standard errors)

\begin{tabular}{|c|c|c|c|c|}
\hline & \multicolumn{2}{|c|}{$\begin{array}{l}\text { Coffee } \\
\left(\begin{array}{ll}n & 20\end{array}\right)\end{array}$} & \multicolumn{2}{|c|}{$\begin{array}{c}\text { Control } \\
(n \mid 8)\end{array}$} \\
\hline & Mean & $\mathrm{SE}$ & Mean & $\mathrm{SE}$ \\
\hline Body-wt (g) & 126 & $4 \cdot 4$ & 124 & 6.1 \\
\hline Liver wt $(\mathrm{g})$ & 6.39 & $0 \cdot 204$ & $6 \cdot 10$ & 0.207 \\
\hline Food intake $(\mathrm{g} / \mathrm{d})$ & $15 \cdot 1$ & 0.21 & $15 \cdot 2$ & 0.27 \\
\hline Fluid intake $(\mathrm{ml} / \mathrm{d})$ & $16 \cdot 4^{* *}$ & 0.79 & $8 \cdot 9$ & 0.28 \\
\hline
\end{tabular}

Mean value was significantly different from that for controls: ${ }^{* *} P<0.01$.

$\dagger$ For details of diets and procedures, see pp. 43I-432.

$20 \mathrm{~g}$ cubed portions and stored frozen. The fatty acid composition of the diet was determined by gas-liquid chromatography after conversion of fatty acids to their methyl esters and was found to comprise the following fatty acids $(\mathrm{g} / \mathrm{kg}): 14: 020,16: 0238,16: 1$ $33,18: 0118,18: 1 n-9362,18: 2 n-6181$, others 48 . The diet provided $14 \%$ of the dietary energy as saturated fatty acids and $215 \mathrm{mg}$ cholesterol $/ 4184 \mathrm{MJ}(1000 \mathrm{kcal})$. The animals were given $20 \mathrm{~g}$ portions of the diet daily and food spillage was recorded. After 1 week on the diet the animals were allocated randomly to two groups which received either boiled coffee or control solution. Both groups continued to receive the semi-synthetic diet. Ground coffee (Kenco medium ground) was prepared exactly as described by Bak \& Grobbee (1989): 1.51 boiling water were added to $60 \mathrm{~g}$ medium-ground coffee in a thermos flask. It was allowed to settle for $1 \mathrm{~h}$ and the coffee solution was carefully decanted. Sucrose $(20 \mathrm{~g} / \mathrm{l})$ was dissolved in the coffee solution. The coffee solution was prepared every $3 \mathrm{~d}$ and the animals were allowed access $a d l i b$. The control group received $a d$ lib. water containing sucrose $(20 \mathrm{~g} / 1)$. Food and fluid intakes were measured throughout the study.

After $28 \mathrm{~d}$ of receiving the coffee, food was withdrawn at 08.00 hours and at 12.00 hours the animals were anaesthetized and blood was collected from the heart using $1 \mathrm{mg} / \mathrm{ml}$ EDTA as anti-coagulant. Plasma was separated within $3 \mathrm{~h}$ of blood collection and plasma lipoproteins were fractionated by ultracentrifugation (Terpstra et al. 1981). Concentrations of cholesterol in plasma and very-low-density-lipoprotein (VLDL), LDL and high-densitylipoprotein (HDL) fractions were determined by enzymic assays (C-System; BoehringerMannheim, Lewes, Sussex). Plasma triacylglycerol concentration was determined enzymically using the Boehringer-Mannheim GPO kit. The results were analysed using a twosample $t$-test.

\section{RESULTS}

Twenty-five animals were allocated to each group, but adequate blood samples were only obtained from twenty animals in the coffee group and eighteen in the control group. Food intakes and body-weights were similar in both groups (Table 1). Fluid intakes were greater in the coffee group $(P<0.01)$. Plasma cholesterol and triacylglycerol concentrations were significantly greater $(P<0.01)$ in the animals given the coffee compared with those given the control solution (Table 2). The increase in total cholesterol concentration was mainly due to an increase in the cholesterol content of LDL and HDL fractions, whereas the cholesterol content of the VLDL fraction was lower in the animals fed on the coffee. 
Table 2. Plasma lipid concentration in Syrian hamsters fed on boiled coffee or control solution $†$

(Mean values with their standard errors)

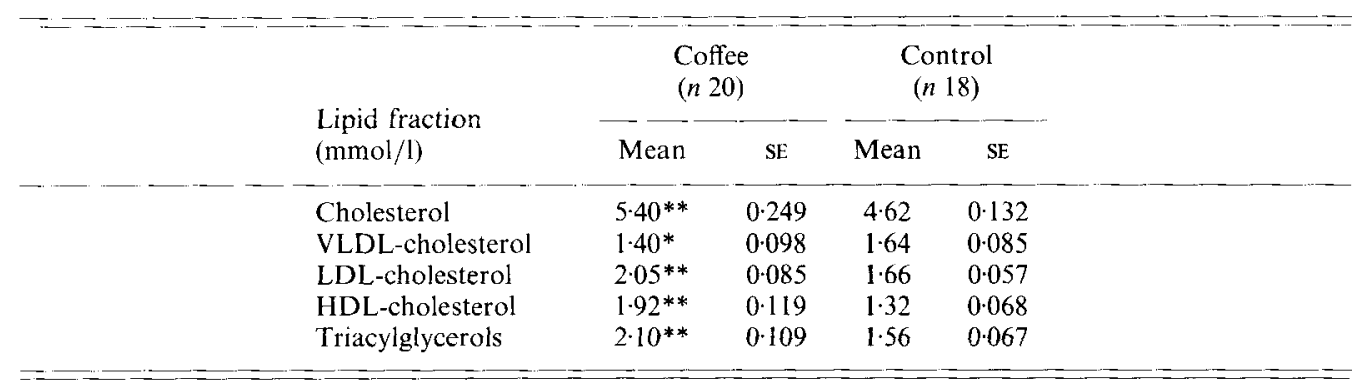

Mean values were significantly different from those of controls: ${ }^{*} P<0 \cdot 05,{ }^{*} P<0 \cdot 01$.

$\dagger$ For details of diets and procedures, see pp. $431-432$.

\section{DISCUSSION}

The diet used in the present study contained a relatively high proportion of saturated fatty acids and cholesterol. In a pilot study (T. A. B. Sanders \& S. Sandaradura, unpublished results) we found the mean plasma cholesterol concentration in animals fed on stock diet to be 1.87 (SE 0.075) $\mathrm{mmol} / 1$ in coffee-fed animals $(n 6)$ compared with 1.56 (SE 0.163) mmol/1 in the controls $(n 6)$. The cholesterol-raising effects of coffee appeared to be exaggerated against the background of a diet high in saturated fatty acids and cholesterol. The increase in plasma cholesterol concentrations with the coffee is equivalent to that seen in man. It was noted that some animals had markedly higher levels of plasma cholesterol than others. We have made similar observations in other studies with different types of saturated fatty acids (T. A. B. Sanders \& S. Sandaradura, unpublished results). It seems likely that genetic influences may determine the response to dietary variation. Selective breeding of diet-responsive strains would decrease the number of animals required in such experiments.

We were particularly careful in the present study to control food and fluid intake. It is possible in some of the human studies that coffee intake may have altered food intake. It is not possible to confirm this as food intakes were not recorded in those studies. In our pilot studies we found it difficult to persuade hamsters to drink coffee unsweetened. Therefore, we added a small amount of sucrose to the coffee. The amount provided was about $328 \mathrm{mg} / \mathrm{d}$ compared with $750 \mathrm{mg} / \mathrm{d}$ provided by the diet. The difference in intakes of sucrose between the coffee group and the control group was slightly higher at $150 \mathrm{mg} / \mathrm{d}$ or $2.34 \mathrm{~kJ}(0.56 \mathrm{kcal}) / \mathrm{d}$ and could not explain the difference in lipid levels. Future studies should consider adjusting the sucrose concentration in the control fluid so that intakes are identical.

The observation that plasma triacylglycerol concentrations, as well as those of total cholesterol, were increased by the coffee possibly points to an effect of coffee on stimulating VLDL synthesis. However, it is to be noted that the concentration of cholesterol in the VLDL fraction was lower in the coffee-fed animals. This might suggest that the conversion of VLDL to LDL may be enhanced by the consumption of coffee. An increase in HDLcholesterol concentration has been noted by other workers (Ohtani et al. 1990) with diets containing saturated fat and cholesterol. HDL is believed to be involved in the reverse transport of cholesterol to the liver. Cholesterol can be transferred to and from HDLcholesterol transfer protein in the transfer of cholesterol to VLDL and LDL (Reich1 \& 
Miller, 1989). The increase in HDL-cholesterol concentration, therefore, could be regarded as the normal physiological response to an increase in LDL-cholesterol. If removal of LDL-cholesterol through the apoB receptor-dependent pathway is partly inhibited, then it is possible that cholesterol could be transferred from LDL to HDL and taken up by the liver via hepatic apoA receptors.

The present study clearly shows that the Syrian hamster can be used as a model to study the cholesterol-raising effects of coffee, but that this has to be carried out against the background of a high intake of saturated fatty acids and cholesterol.

\section{REFERENCES}

Bak, A. A. \& Grobbee, D. E. (1989). The effect on serum cholesterol levels of coffee brewed by filtering or boiling. New England Journal of Medicine 321, 1432-1437.

Ohtani, H., Hayashi, K., Hirata, Y., Dojo, S., Nakashima, K., Nishio, E., Kurushima, H., Saeki, M. \& Kajiyama, G. (1990). Effects of dietary cholesterol and fatty acids on plasma cholesterol level and hepatic protein metabolism. Journal of Lipid Research 31, 1413-1422.

Reichl, D. \& Miller, N. E. (1989). Pathophysiology of reverse cholesterol transport. Insights from inherited disorders of lipoprotein metabolism. Arteriosclerosis 9, 785-797.

Spady, D. K. \& Dietschy, J. M. (1988). Interaction of dietary cholesterol and triglycerides in the regulation of hepatic low density lipoprotein transport in the hamster. Journal of Clinical Investigation 81, 300-309.

Spady, D. K. \& Dietschy, J. M. (1989). Interaction of aging and dietary fat in the regulation of low density lipoprotein transport in the hamster. Journal of Lipid Research 30, 559-569.

Terpstra, A. H. M., Woodward, C. J. H. \& Sanchez-Muniz, F. J. (1981). Improved techniques for separation of serum lipoproteins by density gradient ultracentrifugation: visualization by prestaining and rapid separation of serum lipoproteins from small volumes of serum. Analytical Biochemistry 111, 149-157.

Thelle, D. S., Heyden, S. \& Fodor, J. G. (1987). Coffee and cholesterol in epidemiological and experimental studies. Atherosclerosis 67, 97-103.

Tverdal, A., Stensvold, I., Solvoll, K., Foss, O. P., Lund-Larsen, P. \& Bjartveit, K. (1990). Coffee consumption and death from coronary heart disease in middle-aged Norwegian men and women. British Medical Journal 300, 566-569.

Widdowson, E. M. (1986). Animals in the service of human nutrition. In Proceedings of the XIIth International Congress of Nutrition, pp. 52-57 [T. G. Taylor and N. K. Jenkins, editors]. London: John Libbey.

Williams, P. T., Wood, P. D., Vranizan, K. M., Albers, J. J., Garay, S. C. \& Taylor, C. B. (1985). Coffee intake and elevated cholesterol and apoprotein B levels in men. Journal of the American Medical Association 253, $1407-1411$.

Zock, P. L., Katan, M. B., Merkus, M. P., van Dusseldorp, M. \& Harrycan, J. L. (1990). Effect of a Iipid-rich fraction from boiled coffee on serum cholesterol. Lancet 335, 1235-1237. 